\title{
What's Eating You? Black Butterfly (Hylesia nigricans)
}

\author{
Carlos González, MD; Laura Sandoval, MD; Adriana Motta, MD; Mariam Rolón, MD
}

\section{PRACTICE POINTS}

- When contact with caterpillars, butterflies, or moths occurs, patients should be advised not to rub or scratch the area or attempt to remove or crush the insect with a bare hand, as this may further spread irritating setae or spines.

- Careful removal of the larva with forceps or a similar instrument, combined with tape stripping of the area and immediate washing with soap and water, can be effective in minimizing exposure.

- Contaminated clothing should be removed and laundered thoroughly.

Lepidopterism refers to the adverse medical effects of contact with insects of the order Lepidoptera, which includes both moths and butterflies. These effects typically result from contact with an insect during the caterpillar (larval) stage. Lepidopterism involves multiple pathologic mechanisms, including direct toxicity of venom and mechanical irritant effects. Clinical patterns associated with contact with lepidoptera include localized stinging reactions, papular urticaria and dermatitis, urticarial wheals, and hemorrhagic diathesis. Accurate diagnosis of symptoms associated with contact with caterpillars, butterflies, or moths is nearly impossible without a reliable history of exposure, as the histology of exposure is nonspecific. Treatment is largely empiric and should be based on symptoms. We report a case of lepidopterism in a patient with acute cutaneous lesions following exposure to an adult-stage black butterfly (Hylesia nigricans).

Cutis. 2021:107:68-70.

7 he order Lepidoptera (phylum Arthropoda, class Hexapoda) is comprised of moths and butterflies. ${ }^{1}$ Lepidopterism refers to a range of adverse medical conditions resulting from contact with these insects, typically during the caterpillar (larval) stage. It involves multiple pathologic mechanisms, including direct toxicity of venom and mechanical irritant effects. ${ }^{2}$ Erucism has been defined as any reaction caused by contact with caterpillars or any reaction limited to the skin caused by contact with caterpillars, butterflies, or moths. Lepidopterism can mean any reaction to caterpillars or moths, referring only to reactions from contact with scales or hairs from adult moths or butterflies, or referring only to cases with systemic signs and symptoms (eg, rhinoconjunctival or asthmatic symptoms, angioedema and anaphylaxis, hemorrhagic diathesis) with or without cutaneous findings, resulting from contact with any lepidopteran source. ${ }^{1}$ Strictly speaking, erucism should refer to any reaction from caterpillars and lepidopterism to reactions from moths or butterflies. Because reactions to both larval and adult lepidoptera can cause a variety of either cutaneous and/or systemic symptoms, classifying reactions into erucism or lepidopterism is only of academic interest. ${ }^{1}$

We report a documented case of lepidopterism in a patient with acute cutaneous lesions following exposure to an adult-stage black butterfly (Hylesia nigricans).

\section{Case Report}

A 21-year-old oil well worker presented with pruritic skin lesions on the right arm and flank of 3 hours' duration. He reported that a black butterfly had perched on his arm while he was working and left a considerable number of small yellowish hairs on the skin, after which an intense pruritus and skin lesions began to develop. He denied other associated symptoms. Physical examination revealed numerous 1 - to $2-\mathrm{mm}$, nonconfluent, erythematous and edematous papules on the right forearm, arm (Figure 1A), and flank. Some abrasions of the skin due to scratching and crusting were noted (Figure 1B). A skin biopsy from the right arm showed a superficial

Dr. González is from the Dermatology Service, Kennedy Hospital, Bogotá, Colombia. Dr. Sandoval is from the Dermatology Program, El Bosque University, Bogotá. Drs. Motta and Rolón are from Simón Bolívar Hospital, Bogotá. Dr. Motta is from the Dermatology Service, and Dr. Rolón is from the Dermatopathology Service.

The authors report no conflict of interest.

Correspondence: Laura Sandoval, MD (laurasando.jg@gmail.com).

doi:10.12788/cutis.0170 
perivascular dermatitis with a mixed infiltrate of polymorphonuclear predominance with eosinophils (Figure 2A). Importantly, a structure resembling an urticating spicule was identified in the stratum corneum (Figure 2B); spicules are located on the abdomen of arthropods and are associated with an inflammatory response in human skin.

Based on the patient's history of butterfly exposure, clinical presentation of the lesions, and histopathologic findings demonstrating the presence of the spicules, the diagnosis of lepidopterism was confirmed. The patient was treated with oral antihistamines and topical steroids for 1 week with complete resolution of the lesions.

\section{Comment}

Epidemiology of Envenomation-Although many tropical insects carry infectious diseases, cutaneous injury can occur by other mechanisms, such as dermatitis caused by contact with the skin (erucism or lepidopterism). Caterpillar envenomation is common, but this phenomenon rarely has been studied due to few reported cases, which hinders a complete understanding of the problem. ${ }^{3}$

The order Lepidoptera comprises 2 suborders: Rhopalocera, with adult specimens that fly during the daytime (butterflies), and Heterocera, which are largely
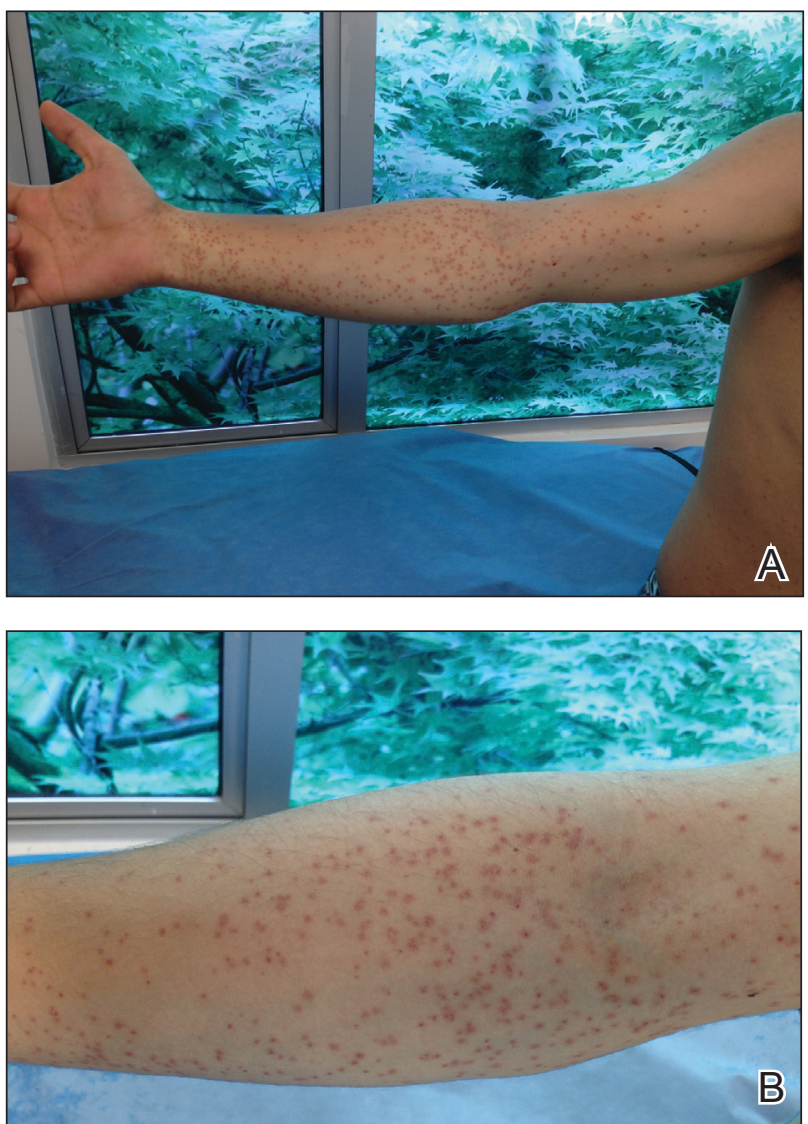

FIGURE 1. A, Numerous 1- to 2-mm, nonconfluent, erythematous and edematous papules on the right arm. B, Some abrasions of the skin due to scratching and crusting were noted. nocturnal (moths). The stages of development include egg, larva (caterpillar), pupa (chrysalis), and adult (imago), constituting a holometabolic life cycle. ${ }^{4}$ Adult butterflies and moths represent the reproductive stage of lepidoptera.

The pathology of lepidopterism is attributed to contact with fluids such as hemolymph and secretions from the spicules, with histamine being identified as the main causative component. ${ }^{3}$ During the reproductive stage, female insects approach light sources and release clouds of bristles from their abdomens that can penetrate human skin and cause an irritating dermatitis. ${ }^{5}$ Lepidopterism can occur following contact with bristles from insects of the Hylesia genus (Saturniidae family), such as in our patient. ${ }^{3,6}$ Epidemic outbreaks have been
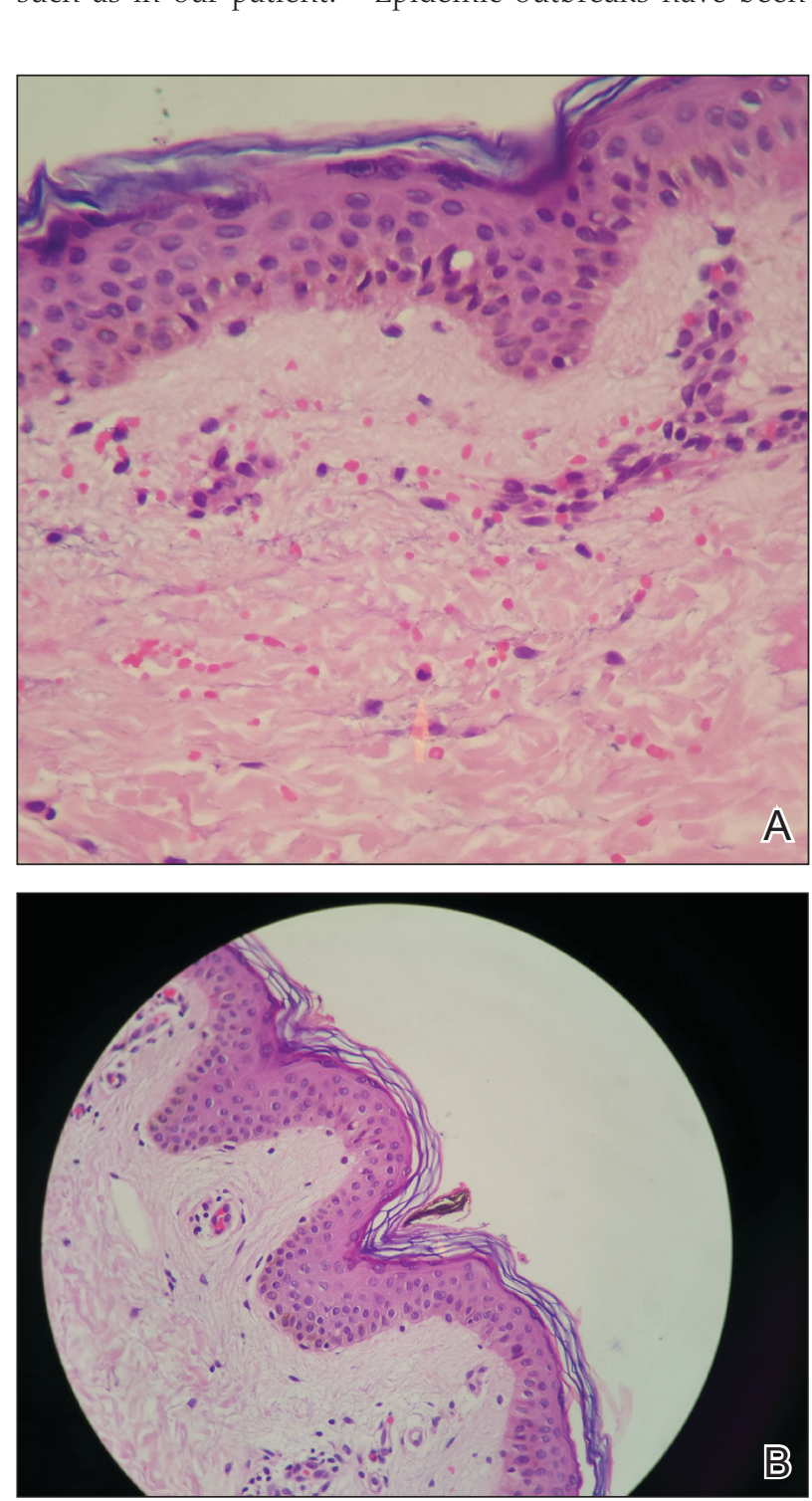

FIGURE 2. A, A biopsy revealed a superficial perivascular dermatitis with a mixed infiltrate of polymorphonuclear predominance with eosinophils present $(\mathrm{H} \& \mathrm{E}$, original magnification $\times 40)$. B, A structure resembling an urticating spicule was identified in the stratum corneum $(\mathrm{H} \& \mathrm{E}$, original magnification $\times 20)$. 
reported in several countries, mainly Argentina, Brazil, and Venezuela. ${ }^{5}$ The patient was located in Colombia, a country without any reported cases of lepidopterism from the black butterfly ( $H$ nigricans). Cutaneous reactions to lepidoptera insects come in many forms, most commonly presenting as a mild stinging reaction with a papular eruption, pruritic urticarial papules and plaques, or scaly erythematous papules and plaques in exposed areas.

Histopathologic Findings-The histology of lepidoptera exposure is nonspecific, typically demonstrating epidermal edema, superficial perivascular lymphocytic infiltrate, and eosinophils. Epidermal necrosis and vasculitis rarely are seen. Embedded spines from Hylesia insects have been described. ${ }^{7}$ The histopathologic examination generally reveals a foreign body reaction in addition to granulomas. ${ }^{3}$

Therapy - The use of oral antihistamines is indicated for the control of pruritus, and topical treatment with cold compresses, baths, and corticosteroid creams is recommended. ${ }^{3,8,9}$

\section{Conclusion}

We report the case of a patient with lepidopterism, a rare entity confirmed histologically with documentation of a spicule in the stratum corneum in the patient's biopsy. Changes due to urbanization and industrialization have a closer relationship with various animal species that are pathogenic to humans; therefore, we encourage dermatologists to be aware of these diseases.

\section{REFERENCES}

1. Hossler EW. Caterpillars and moths: part I. dermatologic manifestations of encounters with Lepidoptera. J Am Acad Dermatol. 2010;62:666.

2. Redd JT, Voorhees RE, Török TJ. Outbreak of lepidopterism at a Boy Scout camp. J Am Acad Dermatol. 2007;56:952-955.

3. Haddad V Jr, Cardoso JL, Lupi O, et al. Tropical dermatology: venomous arthropods and human skin: part I. Insecta. J Am Acad Dermatol. 2012;67:331.

4. Cardoso AEC, Haddad V Jr. Accidents caused by lepidopterans (moth larvae and adult): study on the epidemiological, clinical and therapeutic aspects. An Bras Dermatol. 2005;80:571-578.

5. Salomón AD, Simón D, Rimoldi JC, et al. Lepidopterism due to the butterfly Hylesia nigricans. preventive research-intervention in Buenos Aires. Medicina (B Aires). 2005;65:241-246.

6. Moreira SC, Lima JC, Silva L, et al. Description of an outbreak of lepidopterism (dermatitis associated with contact with moths) among sailors in Salvador, State of Bahia. Rev Soc Bras Med Trop. 2007;40:591-593.

7. Hossler EW. Caterpillars and moths: part II. dermatologic manifestations of encounters with Lepidoptera. J Am Acad Dermatol. 2010;62:666.

8. Maier H, Spiegel W, Kinaciyan T, et al. The oak processionary caterpillar as the cause of an epidemic airborne disease: survey and analysis. $\mathrm{Br} \mathrm{J}$ Dermatol. 2003;149:990-997.

9. Herrera-Chaumont C, Sojo-Milano M, Pérez-Ybarra LM. Knowledge and practices on lepidopterism by Hylesia metabus (Cramer, 1775) (Lepidoptera: Saturniidae) in Yaguaraparo parish, Sucre state, northeastern Venezuela. Revista Biomédica. 2016;27:11-23. 